\title{
Global Issues of Radiopharmaceutical Access and Availability: A Nuclear Medicine Global Initiative Project
}

\author{
Cathy S. Cutler ${ }^{1}$, Elizabeth Bailey ${ }^{2}$, Vijay Kumar ${ }^{3}$, Sally W. Schwarz ${ }^{4}$, Hee-Seung Bom ${ }^{5}$ Jun Hatazawa ${ }^{6}$, Diana Paez ${ }^{7}$, \\ Pilar Orellana ${ }^{7}$, Lizette Louw ${ }^{8}$, Fernando Mut ${ }^{9}$, Hiroki Kato ${ }^{10}$, Arturo Chiti ${ }^{11}$, Savvas Frangos ${ }^{12}$, Frederic Fahey ${ }^{13}$, \\ Gary Dillehay ${ }^{14}$, Seung J. Oh ${ }^{15}$, Dong S. Lee ${ }^{16}$, Sze-Ting Lee ${ }^{17}$, Rodolfo Nunez-Miller ${ }^{7,18}$, Guru Bandhopadhyaya ${ }^{19}$, \\ Prasanta K. Pradhan ${ }^{20}$, and Andrew M. Scott ${ }^{17}$
}

\begin{abstract}
${ }^{1}$ Brookhaven National Laboratory, Upton, New York; ${ }^{2}$ Department of Nuclear Medicine, Royal North Shore Hospital, Sydney, New South Wales, Australia; ${ }^{3}$ Department of Nuclear Medicine and PET, Westmead Hospital and Children's Hospital at Westmead, and University of Sydney, New South Wales, Australia; ${ }^{4}$ Washington University School of Medicine, St Louis, Missouri; ${ }^{5}$ Department of Nuclear Medicine, Chonnam National University Hwasun Hospital, Jeollanam, Korea; ${ }^{6}$ Department of Quantum Cancer Therapy, Research Center for Nuclear Physics, Osaka University, Osaka, Japan; ${ }^{7}$ Nuclear Medicine and Diagnostic Imaging Section, International Atomic Energy Agency, Vienna, Austria; ${ }^{8}$ Department of Nuclear Medicine, Charlotte Maxeke Johannesburg Academic Hospital and University of Witwatersrand, Johannesburg, South Africa; ${ }^{9}$ Nuclear Medicine Service, Italian Hospital, Montevideo, Uruguay; ${ }^{10}$ Department of Nuclear Medicine and Tracer Kinetics, Osaka University Graduate School of Medicine, Osaka, Japan; ${ }^{11}$ Department of Biomedical Sciences, Humanitas University, and Nuclear Medicine Unit, Humanitas Research Hospital-IRCCS, Milan, Italy; ${ }^{2}$ Department of Nuclear Medicine, Bank of Cyprus Oncology Center, Nicosia, Cyprus; ${ }^{13}$ Department of Radiology, Boston Children's Hospital, Harvard Medical School, Boston, Massachusetts; ${ }^{14}$ Department of Radiology, Division of Nuclear Medicine, Robert H. Lurie Comprehensive Cancer Center, Northwestern University Feinberg School of Medicine, Chicago, Illinois; ${ }^{15}$ Department of Nuclear Medicine, Asan Medical Center, University of Ulsan College of Medicine, Seoul, Korea; ${ }^{16}$ Department of Nuclear Medicine, Seoul National University College of Medicine, Seoul, Korea; ${ }^{17}$ Department of Molecular Imaging and Therapy, Austin Health; University of Melbourne; Olivia Newton-John Cancer Research Institute, and School of Cancer Medicine, La Trobe University, Melbourne, Australia; ${ }^{18}$ Excel Diagnostics and Nuclear Oncology Center, Houston, Texas; ${ }^{19}$ Department of Nuclear Medicine, All India Institute of Medical Sciences, Ansari Nagar, New Delhi, India; and ${ }^{20}$ Department of Nuclear Medicine, Sanjay Gandhi Post Graduate Institute of Nuclear Medicine, Lucknow, India
\end{abstract}

The Nuclear Medicine Global Initiative was formed in 2012 by 13 international organizations to promote human health by advancing the field of nuclear medicine and molecular imaging by supporting the practice and application of nuclear medicine. The first project focused on standardization of administered activities in pediatric nuclear medicine and resulted in 2 articles. For its second project the Nuclear Medicine Global Initiative chose to explore issues impacting on access and availability of radiopharmaceuticals around the world. Methods: Information was obtained by survey responses from 35 countries on available radioisotopes, radiopharmaceuticals, and kits for diagnostic and therapeutic use. Issues impacting on access and availability of radiopharmaceuticals in individual countries were also identified. Results: Detailed information on radiopharmaceuticals used in each country, and sources of supply, was evaluated. Responses highlighted problems in access, particularly due to the reliance on a sole provider, regulatory issues, and reimbursement, as well as issues of facilities and workforce, particularly in low- and middle-income countries. Conclusion: Strategies to address access and availability of radiopharmaceuticals are outlined, to enable timely and equitable patient access to nuclear medicine procedures worldwide. In the face of disruptions to global supply chains by the coronavirus disease 2019 outbreak, renewed focus on ensuring a reliable supply

Received Apr. 11, 2020; revision accepted Jun. 15, 2020.

For correspondence or reprints contact: Andrew M. Scott, Department of Molecular Imaging and Therapy, Austin Health, Studley Rd., Heidelberg, VIC, 3084, Australia.

E-mail: andrew.scott@austin.org.au

Published online Jul. 9, 2020.

COPYRIGHT (C) 2021 by the Society of Nuclear Medicine and Molecular Imaging. of radiopharmaceuticals is a major priority for nuclear medicine practice globally.

Key Words: radiopharmaceuticals; access; global issues

J Nucl Med 2021; 62:422-430

DOI: 10.2967/jnumed.120.247197

$\mathbf{E}$ very year more than 30 million patients are diagnosed or treated using nuclear medicine and molecular imaging techniques (1). Nuclear medicine comprises diagnostic and therapeutic techniques that use radiopharmaceuticals for applications such as oncology, cardiovascular disorders, and neurologic disorders to provide information at both the molecular and the cellular level for probing, tracking tissue function, evaluating disease progression, supporting treatment planning, guiding tissue sampling, and assessing treatment responses $(2,3)$. Nuclear medicine and molecular imaging procedures are among the most powerful analytic tools available today, providing physicians with critical patient information on which important medical decisions are based $(3,4)$. These procedures and therapies are a key component to personalized medicine, without which, patients may be required to undergo more invasive and more costly tests and even invasive surgeries $(1,3)$. The International Atomic Energy Agency (IAEA) launched in September 2019 IMAGINE (the IAEA Medical Imaging and Nuclear Medicine Global Resources Database), a comprehensive database on availability of nuclear medicine and diagnostic imaging equipment worldwide (5). According to IMAGINE, over 140 
countries have availability of SPECT or SPECT/CT, with close to 27,000 systems installed, whereas 109 have PET/CT and over 5,200 systems. The use of nuclear medicine procedures varies between countries, in part due to costs, regulatory issues, training of workforce, and availability of radiopharmaceuticals, although the relative contribution of each of these factors is not well defined $(6,7)$.

In 2014, the first Nuclear Medicine Global Initiative (NMGI) reported on the standardization of administered activities in pediatric patients $(8,9)$. Based on the success of this first project it was decided that the second project of the NMGI would be to assess the availability of diagnostic and therapeutic radiopharmaceuticals by country and region, to collate and analyze the data and develop a report outlining the current availability and issues preventing patient access to these resources. The aim of the project was to collate information regarding the availability of radiopharmaceuticals worldwide, including the availability of cold kits, generators, and radionuclides; use of central pharmacies; listing of radiopharmaceuticals required but not available; and identification of issues impeding use of radiopharmaceuticals such as access, shipping, cost, regulatory requirements, facilities, and training. This information could inform actions that could be taken to mitigate the identified barriers, ensure improved patient access, and encourage commercial interest and research and development in the field.

\section{MATERIALS AND METHODS}

A detailed questionnaire on radiopharmaceutical access, availability, and issues relating to supply and access (supplemental materials; available at http://jnm.snmjournals.org) was sent to key contacts and the nuclear medicine societies (where existing) of all countries listed in the IAEA database. This questionnaire was developed by the NMGI project members (Table 1) and was made available by the Society of Nuclear Medicine and Molecular Imaging (SNMMI) through a secure online portal or through direct correspondence with country nuclear medicine societies. The information obtained was confirmed as applicable for the entire country and was based on country internal information gathering and data compilation. The responses were correlated into continental regions, and whether countries were of low, low-middle, high-middle, or high income, according to World Bank income classification (10). Data were compiled and summarized, with verification of information if gaps in initial responses were identified.

\section{RESULTS}

A total of 35 countries provided complete data for the survey and are listed in Table 2. Of the country responders, 16 were from the Asia-Pacific region, including Australia, 4 countries responded from Europe, 8 from Africa, 5 from Latin America, and both the United States and Canada. To facilitate the analysis, Mexico was included in Latin America. Based on data from the IMAGINE database (5) on individual country activity (numbers of SPECT and PET cameras), this cohort represents $76.4 \%$ of global SPECT camera sites and $71.1 \%$ of global PET camera sites (Table 3).

For North America, Latin America, and Australia the data represent $91.3 \%-100.0 \%$ of nuclear medicine camera sites, whereas in Asia more than $73 \%$ of sites are represented. African country responses were more than $50 \%$ of nuclear medicine camera sites, with responses from both low-income and middle-income countries with nuclear medicine sites. Country responses from Europe were low, which reflected the challenges in obtaining accurate country-based data in this region for the purpose of this analysis.
TABLE 1

NMGI Organizations and Representatives

\begin{tabular}{|c|c|}
\hline Organization & Representatives \\
\hline \multirow[t]{4}{*}{ SNMMI } & Cathy S. Cutler \\
\hline & Sally Schwarz \\
\hline & Fred Fahey \\
\hline & Gary Dillehay \\
\hline \multirow{2}{*}{$\begin{array}{l}\text { World Federation of Nuclear } \\
\text { Medicine and Biology }\end{array}$} & Andrew Scott \\
\hline & Sze Ting Lee \\
\hline $\begin{array}{l}\text { Latin American Association } \\
\text { of Societies of Biology } \\
\text { and Nuclear Medicine }\end{array}$ & Fernando Mut \\
\hline \multirow{2}{*}{$\begin{array}{l}\text { Australian and New Zealand } \\
\text { Society of Nuclear Medicine }\end{array}$} & Vijay Kumar \\
\hline & Elizabeth Bailey \\
\hline $\begin{array}{l}\text { Asia Oceania Federation of Nuclear } \\
\text { Medicine and Biology }\end{array}$ & $\begin{array}{l}\text { Henry Hee-Seung } \\
\text { Bom }\end{array}$ \\
\hline $\begin{array}{l}\text { Asian Regional Cooperative } \\
\text { Council for Nuclear Medicine }\end{array}$ & Jun Hatazawa \\
\hline China Society of Nuclear Medicine & Lin Li \\
\hline \multirow{2}{*}{$\begin{array}{l}\text { European Association of } \\
\text { Nuclear Medicine }\end{array}$} & Arturo Chiti \\
\hline & Savvas Frangos \\
\hline \multirow[t]{4}{*}{ IAEA } & Ravi Kashyap \\
\hline & Rodolfo Nunez-Miller \\
\hline & Pilar Orellana \\
\hline & Diana Paez \\
\hline Japan Society of Nuclear Medicine & Hiroki Kato \\
\hline \multirow[t]{2}{*}{ Korea Society of Nuclear Medicine } & Seung Jun Oh \\
\hline & Dong Soo Lee \\
\hline $\begin{array}{l}\text { South African Society of } \\
\text { Nuclear Medicine }\end{array}$ & Lizette Louw \\
\hline \multirow[t]{2}{*}{ Society of Nuclear Medicine, India } & $\begin{array}{l}\text { Guru } \\
\text { Bandhopadhyaya }\end{array}$ \\
\hline & $\begin{array}{l}\text { Prasanta } \\
\text { K. Pradhan }\end{array}$ \\
\hline
\end{tabular}

\section{9mTc Generators}

Responders were asked to name the manufacturer and supplier of ${ }^{99 \mathrm{~m} T c}$ generators (Table 4). There were $32{ }^{99 \mathrm{~m}} \mathrm{Tc}$ generator suppliers globally, with 18 only supplying to a single country, leaving only 10 manufacturers that supply to multiple continents or countries and 6 producers that supply to 4 or more countries. The United States is the major user of ${ }^{99 \mathrm{~m}} \mathrm{Tc}$, representing approximately $50 \%$ of the global market even though it relies on only 3 suppliers of generators. The supply to Africa is the most limited, with most countries reliant on a single generator supplier. The Asia-Pacific region has a large number of suppliers of generators, often imported from Europe, but also locally produced. It is probable that the data for Europe are not representative of the actual situation due to the limited number of respondents from European countries. 
TABLE 2

Countries Responding to Survey

\begin{tabular}{|c|c|c|}
\hline Country & Region & Income category \\
\hline United States & North America & $\mathrm{HIC}$ \\
\hline Canada & North America & $\mathrm{HIC}$ \\
\hline Brazil & Latin America & UMIC \\
\hline Chile & Latin America & $\mathrm{HIC}$ \\
\hline Mexico & Latin America & UMIC \\
\hline Colombia & Latin America & UMIC \\
\hline Uruguay & Latin America & $\mathrm{HIC}$ \\
\hline Australia & Australia & $\mathrm{HIC}$ \\
\hline Japan & Asia & $\mathrm{HIC}$ \\
\hline Korea & Asia & $\mathrm{HIC}$ \\
\hline Bangladesh & Asia & LMIC \\
\hline India & Asia & LMIC \\
\hline Indonesia & Asia & LMIC \\
\hline Iran & Asia & UMIC \\
\hline Israel & Asia & $\mathrm{HIC}$ \\
\hline Jordan & Asia & UMIC \\
\hline Malaysia & Asia & UMIC \\
\hline Mongolia & Asia & LMIC \\
\hline Pakistan & Asia & LMIC \\
\hline Philippines & Asia & LMIC \\
\hline Singapore & Asia & $\mathrm{HIC}$ \\
\hline Taiwan & Asia & UMIC \\
\hline Thailand & Asia & UMIC \\
\hline Algeria & Africa & UMIC \\
\hline Ghana & Africa & LMIC \\
\hline Morocco & Africa & LMIC \\
\hline Niger & Africa & LIC \\
\hline South Africa & Africa & UMIC \\
\hline Tanzania & Africa & LIC \\
\hline Uganda & Africa & LIC \\
\hline Zambia & Africa & LMIC \\
\hline Austria & Europe & $\mathrm{HIC}$ \\
\hline Cyprus & Europe & HIC \\
\hline Estonia & Europe & $\mathrm{HIC}$ \\
\hline Poland & Europe & $\mathrm{HIC}$ \\
\hline
\end{tabular}

HIC = high-income country; UMIC = upper-middle-income country; LMIC = lower-middle-income country; LIC = low-income country.

Data are from World Bank (10).

\section{Cold Kits}

The concept of the cold kit which contains all the ingredients except the radionuclide was developed originally at Brookhaven National Laboratory $(11,12)$ to simplify the production of radiopharmaceuticals and enable consistent formulation at multiple sites to support clinical trials and eventual drug development. Figure 1 shows the number of countries where the most commonly used cold kits for radiopharmaceuticals were available.
Tables 5 and 6 list the 53 companies indicated in the survey that sell cold kits for radiopharmaceutical preparation and the continents they supply. Over half of the 33 radiopharmaceutical kit manufacturers provide to only a single country, 8 provide cold kits to 2 countries, 1 manufacturer supplies to 3 countries, 5 manufacturers supply to 4 countries, and 6 distribute to 5 or more countries. The data for the United States indicated only 8 suppliers for diagnostic kits and 5 suppliers of kits for therapeutics, with local pharmacies supplying ${ }^{131}$ I capsules and solutions.

Responders were further asked to state the radiopharmaceuticals they used by imaging category and their utility in each category. The responses were divided into 3 groups: SPECT imaging, PET imaging, and therapy.

\section{SPECT Radiopharmaceuticals}

Figure 2 shows the radiopharmaceuticals used for SPECT diagnostic imaging and the number of countries where they are

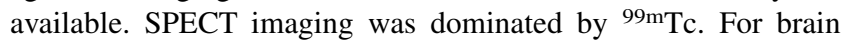
imaging a total of 13 different radiopharmaceuticals were listed, with the highest country use-based on survey responses-being ${ }^{99 \mathrm{~m}}$ Tc-hexamethylpropyleneamine oxime and ${ }^{99 \mathrm{~m}} \mathrm{Tc}$-diethylenetriaminepentaacetic acid at $74 \%$, followed by $99 \mathrm{mTc}$-ethylcysteinate dimer at $51 \%$. For thyroid imaging the most commonly used was ${ }^{99 m}$ Tc-pertechnetate at $89 \%$ followed by ${ }^{131} \mathrm{I}$ at $86 \%$. Parathyroid imaging had ${ }^{99 \mathrm{~m}}$ Tc-sestamibi, with the highest use at $97 \%$, followed by ${ }^{99 \mathrm{~m}} \mathrm{Tc}$-pertechnetate at $80 \%$ for subtraction scanning, and ${ }^{201} \mathrm{Tl}$ at $23 \%$. For pulmonary imaging the highest use was seen for ${ }^{99 \mathrm{~m}} \mathrm{Tc}$-macroaggregated albumin at $86 \%$ for perfusion scans, followed by ${ }^{99 \mathrm{~m}} \mathrm{Tc}$-diethylenetriaminepentaacetic acid aerosol at 63\%, and Technegas (Cyclomedica Asia Pacific) at 34\% for ventilation scans. Cardiac myocardial perfusion imaging had ${ }^{99 \mathrm{~m}} \mathrm{Tc}-$ sestamibi with the highest use at $94 \%$, and ${ }^{201} \mathrm{Tl}$-chloride and ${ }^{99} \mathrm{~m}$ Tc-tetrofosmin having similar use at $45 \%$.

The liver/biliary agent demonstrating the highest use is ${ }^{99 \mathrm{~m}} \mathrm{Tc}-$ hepatoiminodiacetic acid at $51 \%$ of countries followed by ${ }^{99 \mathrm{~m}} \mathrm{Tc}-$ macroaggregated albumin at $43 \%$ (shunt studies), ${ }^{99 \mathrm{~m}} \mathrm{Tc}-$ mebrofenin at $40 \%$, and ${ }^{99 \mathrm{~m}} \mathrm{Tc}$-sulfur colloid at $34 \%$. For imaging the spleen and bone marrow the most highly used agents were ${ }^{99 \mathrm{~m}} \mathrm{Tc}$-denatured red blood cells at $43 \%$ (for spleen imaging), followed by ${ }^{99 \mathrm{~m}} \mathrm{Tc}$-sulfur colloid at $34 \%$ and ${ }^{99 m}$ Tc-tin colloid at $31 \%$. The agent with the highest use for renal imaging was ${ }^{99 \mathrm{~m}} \mathrm{Tc}$-diethylenetriaminepentaacetic acid at $94 \%$, followed by ${ }^{99 \mathrm{~m}} \mathrm{Tc}$-dimercaptosuccinic acid at $89 \%$

TABLE 3

Survey Countries' Representation of Regional Nuclear Medicine Activity

\begin{tabular}{lcc}
\hline \multicolumn{1}{c}{ Region } & SPECT cameras (\%) & PET cameras (\%) \\
\hline North America & 100.0 & 100.0 \\
\hline Latin America & 94.9 & 91.3 \\
\hline Europe & 5.1 & 5.0 \\
Africa & 53.9 & 57.9 \\
Asia & 73.5 & 74.3 \\
Australia & 100.0 & 100.0 \\
Global & 76.4 & 71.1 \\
\hline
\end{tabular}

SPECT and PET camera numbers are based on IMAGINE database (5). 
TABLE 4

Technetium Generator Suppliers

\begin{tabular}{|c|c|c|c|c|c|}
\hline Supplier & Total no. of countries & United States and Canada & Europe & Asia-Pacific & Africa \\
\hline GE & 7 & 1 & 3 & 2 & 1 \\
\hline IBA/CIS Bio France & 10 & & 1 & 8 & 1 \\
\hline Monrol & 4 & & & 3 & 1 \\
\hline Polatom & 5 & & 1 & 2 & 2 \\
\hline ANSTO & 2 & & & 2 & \\
\hline BAEC (Bangladesh) & 1 & & & 1 & \\
\hline IPEN & 3 & 2 & 1 & & \\
\hline Mallinckrodt/Covidien & 6 & 1 & 1 & 4 & \\
\hline Amersham & 4 & & & & 4 \\
\hline Parsisotope (Iran) & 3 & & & 3 & \\
\hline Sam Young Unitech (Korea) & 1 & & & 1 & \\
\hline Pinstech (Pakistan) & 1 & & & 1 & \\
\hline BRIT (India) & 1 & & & 1 & \\
\hline Jubilant DraxImage & 1 & & & 1 & \\
\hline Saxons Health Care & 1 & & & 1 & \\
\hline SDS Life Sciences & 1 & & & 1 & \\
\hline Vishat Diagnostic Priv. Ltd. & 1 & & & 1 & \\
\hline Polatom & 2 & & 1 & 1 & \\
\hline NTP South Africa & 2 & & & & 2 \\
\hline Lantheus & 3 & 2 & & 1 & \\
\hline Rotop & 2 & 1 & & 1 & \\
\hline BSM & 1 & 1 & & & \\
\hline Nihon Medi-Physics Co Ltd. (Japan) & 1 & & & & 1 \\
\hline Fujifilm RI Pharma (Japan) & 3 & & & 2 & 1 \\
\hline CGM Nuclear & 1 & 1 & & & \\
\hline Positronpharma (Chile) & 1 & 1 & & & \\
\hline Comision Chilena Energia Nuclear (Chile) & 1 & 1 & & & \\
\hline Elumatac & 1 & & & 1 & \\
\hline Quantarad Priv. Ltd. & 1 & & & 1 & \\
\hline Pinstech & 1 & & & 1 & \\
\hline MDS Nordion (Canada) & 1 & 1 & & & \\
\hline Alumina Chrom Column & 1 & 1 & & & \\
\hline
\end{tabular}

and ${ }^{99 \mathrm{~m}} \mathrm{Tc}-\mathrm{mercaptoacetyltriglycine}$ at $83 \%$. Adrenal imaging is performed predominantly with ${ }^{131}$ I-metaiodobenzylguanidine (MIBG) at $60 \%$, followed by ${ }^{123} \mathrm{I}-\mathrm{MIBG}$ at $37 \%,{ }^{131} \mathrm{I}$-norcholesterol at $17 \%$, and ${ }^{131} \mathrm{I}$-aldosterol at $11 \%$. For bone scanning, ${ }^{99 \mathrm{~m} T c-m e t h-}$ ylene diphosphonate was the most common at $97 \%$, followed by ${ }^{99 \mathrm{~m}} \mathrm{Tc}$-hydroxymethylene diphosphonate at $34 \%$ and ${ }^{99 \mathrm{~m}} \mathrm{Tc}$-hydroxymethylene diphosphonate at $29 \%$. For gastrointestinal imaging the highest use was observed for ${ }^{99 \mathrm{~m}} \mathrm{Tc}$-pertechnetate at $71 \%$, followed by ${ }^{99 \mathrm{~m}} \mathrm{Tc}$-sulfur colloid and ${ }^{99 \mathrm{~m}} \mathrm{Tc}$-red blood cells at $57 \%$.

For SPECT tumor imaging, the highest use by responders was ${ }^{131} \mathrm{I}-\mathrm{MIBG}$ at $60 \%$, followed by ${ }^{67} \mathrm{Ga}$-citrate at $46 \%,{ }^{201} \mathrm{Tl}$-chloride at $43 \%$, and ${ }^{123} \mathrm{I}-\mathrm{MIBG}$ at $34 \%$. A total of 10 agents were supplied by responders as being used for infection and inflammation imaging. The most highly used was ${ }^{99 \mathrm{~m}} \mathrm{Tc}$-radiolabeled $\mathrm{WBC}$ at $57 \%$, followed by ${ }^{67} \mathrm{Ga}$-citrate at $49 \%$ and LeukoScan (sulesomab; Immunomedics, Inc.) and ciprofloxacin at $11 \%$.
Sentinel lymph node imaging was reported to be performed with 7 agents, 3 of which are restricted to use in a single country. Those used in multiple countries are ${ }^{99 \mathrm{~m}} \mathrm{Tc}$-nanocolloid with a use of $74 \%,{ }^{99 \mathrm{~m} T c-s u l f u r}$ colloid with a use of $20 \%$, ${ }^{99 \mathrm{~m} T c-a n t i m o n y}$ colloid at $11 \%$, and ${ }^{99 m}$ Tc-phytate at $9 \%$. South Africa was the sole user of ${ }^{131}$ I-sunflower oil for confirmation and localization of a lymphatic leak. In vitro studies were performed using only 4 agents: ${ }^{14} \mathrm{C}$-urea at $26 \%$ use, ${ }^{51} \mathrm{Cr}$-chromate at $17 \%,{ }^{51} \mathrm{Cr}$-ethylenediaminetetraacetic acid at $9 \%$, and ${ }^{125} \mathrm{I}$-human serum albumin at $6 \%$. These agents see limited use due to restricted availability.

\section{PET Radiopharmaceuticals}

Of the 35 countries that provided responses to the survey, only 28 indicated they provided PET services. Low- and low-middle income countries had the lowest numbers of PET sites. Survey responders indicated they used a total of 34 PET agents, and 5 


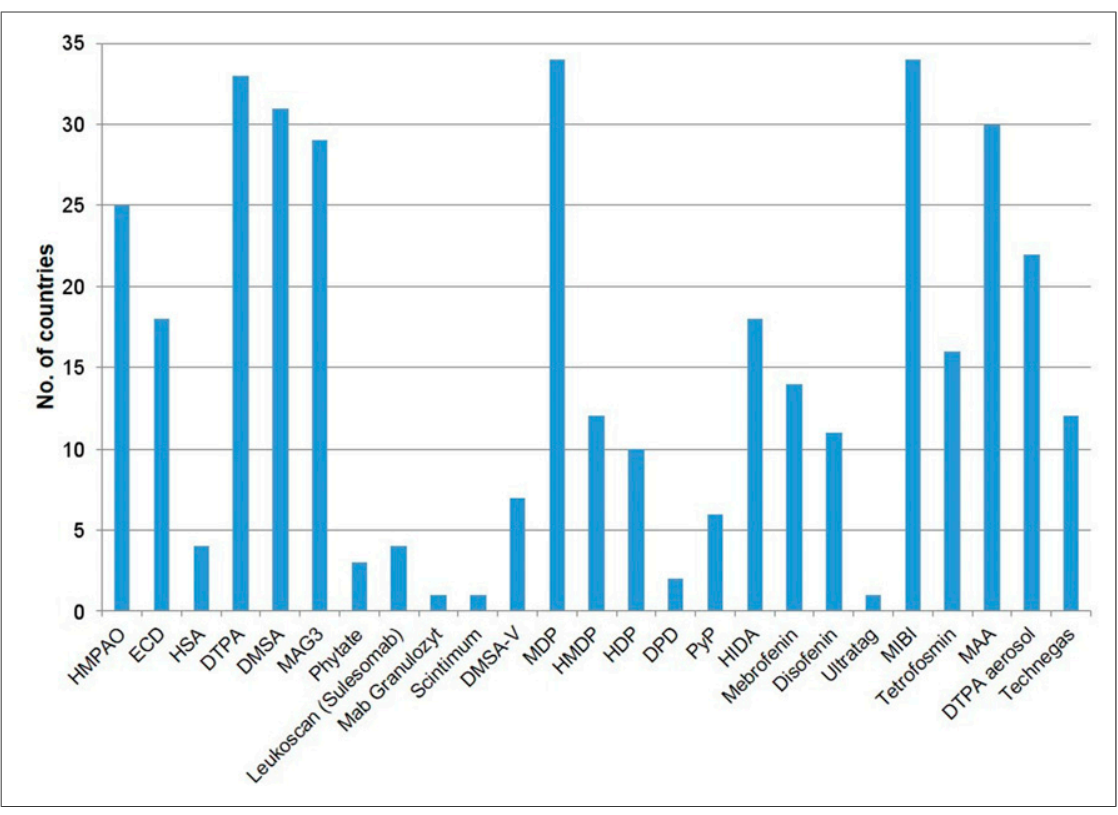

FIGURE 1. Range of most commonly available cold kits and ventilation agents in countries surveyed.

radiometal radionuclides $\left({ }^{82} \mathrm{Sr} /{ }^{82} \mathrm{Rb},{ }^{64} \mathrm{Cu},{ }^{89} \mathrm{Zr},{ }^{68} \mathrm{Ga}\right.$, and $\left.{ }^{44} \mathrm{Sc}\right)$ were listed (Fig. 3). The most highly used PET agent is ${ }^{18}$ F-FDG (Fig. 3A). Eleven other ${ }^{18}$ F-labeled PET agents were listed (Fig. 3B).

${ }^{68} \mathrm{Ga}$ has experienced significant growth due to its availability via a long-lived generator that now sees wide availability. The most highly used ${ }^{68} \mathrm{Ga}$ tracer was ${ }^{68} \mathrm{Ga}$-prostate-specific membrane antigen, which is at $50 \%$ use, followed by ${ }^{68} \mathrm{Ga}$-DOTATATE (also known as NETSPOT; Advanced Accelerator Applications) at $46 \%$ and ${ }^{68} \mathrm{Ga}$-DOTATOC at $25 \%$ use (Fig. $3 \mathrm{C}$ ).

Several radiopharmaceutical agents have been developed with ${ }^{11} \mathrm{C}$, and the 2 most highly used were ${ }^{11} \mathrm{C}$-methionine and ${ }^{11} \mathrm{C}$ choline at $32 \%$, followed by ${ }^{11} \mathrm{C}$-Pittsburgh compound $\mathrm{B}$, which is used at $25 \%$ (Fig. 3D).

\section{Therapeutic Radiopharmaceuticals}

The use of radiopharmaceuticals for therapeutic applications is shown in Figure 4, and for ${ }^{131}$ I (imaging and also therapeutic use) in Figure 2. The responses indicated limited use other than ${ }^{131} \mathrm{I}$, mainly due to limited access and high cost. ${ }^{131}$ I was used for hyperthyroidism in $94 \%$ of countries and for thyroid cancer in $91 \%$ of countries. A total of 16 radiopharmaceuticals were provided by responders as being used for therapy, with the next most prevalently used being ${ }^{153} \mathrm{Sm}$-ethylenediaminetetramethylene phosphonate for bone pain palliation at $51 \%$ use, and ${ }^{131}$ I-MIBG was used in $51 \%$ of countries. ${ }^{177} \mathrm{Lu}$-DOTATATE was reported to have $29 \%$ use, ${ }^{177} \mathrm{Lu}$-DOTATOC $11 \%$, and ${ }^{90}$ Y-DOTATATE $11 \% .{ }^{177} \mathrm{Lu}$-prostate-specific membrane antigen was mainly under research use at the time of the survey. Restricted availability of ${ }^{32} \mathrm{P}$ was noted, with several countries indicating they would use ${ }^{32} \mathrm{P}$ if it was available.

\section{Training and Education}

All countries noted a lack of trained and qualified staff to perform certain tasks, including radiopharmaceutical quality assurance and quality control, cell labeling, production, manufacturing, and final dispensing. Low-income and low-middle-income countries in particular identified the lack of education and training of staff, including clinicians, physicists, radiochemists, and radiopharmacists, as a barrier to providing certain services. This resulted in their being unable to offer complex procedures such as cell labeling, radionuclide therapy such as ${ }^{177} \mathrm{Lu}$-targeted therapies, and other new radiopharmaceutical tracers that required in-house quality control and quality assurance. Even in some high-income countries, a lack of training in quality control/quality assurance and good manufacturing practices, as well as drug release and radiation safety personnel, were noted as inhibiting growth and patient access.

\section{DISCUSSION}

This project has highlighted several important issues regarding radiopharmaceutical access and availability at a global level. As with the first NMGI project, there was variability in response among countries and regions; however, the survey obtained country-based responses that covered approximately $75 \%$ of global nuclear medicine sites. Moreover, the data obtained spanned all geographical regions and country income statuses (Table 3). Although there were limited data available from European countries, the results from comparable socioeconomic countries with similar nuclear medicine infrastructure (IMAGINE database) in our cohort suggest that our data still provide a valuable portrayal of the current availability and use of nuclear medicine and the challenges that restrict its use and future growth.

Despite multiple efforts including the IAEA, the U.S. Department of Energy, Nuclear Medicine Europe, and high-level working groups to ensure a sustainable supply of ${ }^{99} \mathrm{Mo} /{ }^{99 m} \mathrm{Tc}$ generator equipment, our survey showed a lack of availability of generators as an ongoing issue, with many countries having only a single supplier, deliveries limited to once a week or once a fortnight, and problems with reliability of supply. This was identified as an issue particularly in low- and middle-income countries. This problem of supply chains has also been highlighted in the recent coronavirus disease 2019 (COVID-19) pandemic, where generator supplies to many countries have been markedly reduced due to flight restrictions (13-16).

The survey data highlight the dependency of the nuclear medicine field and individual countries on single-source manufacturers or distributers of their radiopharmaceutical cold kits. There were several cold kits that are no longer available, especially in developing countries, including ${ }^{99 \mathrm{~m}} \mathrm{Tc}$-hepatoiminodiacetic acid, sulfur colloid, antimony colloid, ${ }^{99 \mathrm{~m}} \mathrm{Tc}$-macroaggregated albumin, ${ }^{99 \mathrm{~m}} \mathrm{Tc}-$ mercaptoacetyltriglycine, brain perfusion agents (both hexamethylpropyleneamine oxime and ${ }^{99 \mathrm{~m}} \mathrm{Tc}$-ethylcysteinate dimer), ${ }^{99 m}$ Tc-hydroxymethylene diphosphonate, and ${ }^{99 \mathrm{~m}} \mathrm{Tc}$-pyrophosphate. This was reported to be due to the high costs to import the products, only having a single sole supplier of cold kits with limited product availability, and regulatory 
TABLE 5

Commercial Radiopharmaceutical Kit Suppliers: Part 1

\begin{tabular}{|c|c|c|c|c|c|}
\hline Supplier & $\begin{array}{c}\text { Total no. of } \\
\text { countries }\end{array}$ & $\begin{array}{l}\text { United States } \\
\text { and Canada }\end{array}$ & Europe & Asia-Pacific & Africa \\
\hline BRIT (India) & 1 & & & 1 & \\
\hline Jubilant DraxImage & 1 & & & 1 & \\
\hline Saxons Healthcare & 1 & & & 1 & \\
\hline SDS Life Sciences & 1 & & & 1 & \\
\hline Vishat Diagnostic Pvt. Ltd. & 1 & & & 1 & \\
\hline Sanlar Imex Service Pvt. Ltd. & 1 & & & 1 & \\
\hline GE & 13 & 1 & 4 & 6 & 2 \\
\hline Polatom & 11 & & 4 & 5 & 2 \\
\hline TINT & 1 & & & 1 & \\
\hline GMS & 2 & & & 2 & \\
\hline Biogenetech & 1 & & & 1 & \\
\hline IBA/CIS Bio & 11 & 1 & 2 & 6 & 2 \\
\hline Mallinckrodt/Covidien & 8 & 1 & 3 & 3 & 1 \\
\hline Monrol & 4 & & & 3 & 1 \\
\hline Izotope & 4 & & & 3 & 1 \\
\hline JPT/IDB & 1 & & & 1 & \\
\hline Bristol-Myers (Hungary and Canada) & 1 & & & & 1 \\
\hline Amersham & 2 & & & & 2 \\
\hline DRAXImage & 4 & 1 & & 1 & 2 \\
\hline AAA & 5 & 1 & 3 & & \\
\hline Bayer & 6 & 1 & 2 & 3 & 1 \\
\hline Nihon Medi-Physics Co Ltd. (Japan) & 1 & & & 1 & \\
\hline Fujifilm RI Pharma (Japan) & 1 & & & 1 & \\
\hline CGM Nuclear (Chile) & 1 & 1 & & & \\
\hline Positronpharma (Chile) & 1 & 1 & & & \\
\hline Coimision Chilena Energia Nuclear (Chile) & 1 & 1 & & & \\
\hline Rotop & 3 & & 1 & 2 & 1 \\
\hline Atomic High Tech China & 1 & & & 1 & \\
\hline Medi-Radiopharma & 4 & & & 3 & 1 \\
\hline Immunomedics & 4 & & 2 & 1 & 1 \\
\hline San Yung Tosh & 2 & & & 1 & \\
\hline Kibion & 1 & & & 1 & \\
\hline Pinstech & 1 & & & 1 & \\
\hline
\end{tabular}

factors (preventing importation). Surprisingly, many countries do not have any access to ventilation agents for performing a ventilation-perfusion scan and commonly perform perfusion-only imaging.

Non- ${ }^{18}$ F-FDG PET tracers had limited availability in most countries, predominantly due to barriers such as high cost, no access to a cyclotron, regulatory restrictions, studies not being funded by healthcare providers, and lack of suppliers. ${ }^{68} \mathrm{Ga}$ generator supply in particular has been identified as restricted in many countries and likely to have increased demand in the future with more widespread clinical use of ${ }^{68} \mathrm{Ga}$-peptide studies.

Many therapeutic tracers were not available due to their high cost, as well as no available supplier or distributor, and lack of regulatory approval. Over the past $10 \mathrm{y}$ there have been significant changes and increases in the regulatory burden regarding production, handling, and transportation of radiopharmaceuticals (17). Most countries did not use or have access to ${ }^{123} \mathrm{I},{ }^{123} \mathrm{I}-\mathrm{MIBG}$, and ${ }^{131} \mathrm{I}$-MIBG mainly due to cost. This is especially true for low- and middle-income countries. Peptide receptor radionuclide and peptide radionuclide ligand therapeutics including ${ }^{177} \mathrm{Lu}$-Lutathera (Advanced Accelerator Applications) had limited use across all countries, although it should be mentioned that this field is rapidly changing, and many more sites and countries will have access to these therapeutic radiopharmaceuticals since the survey was completed.

The data obtained in this survey project clearly show that all countries have issues of radiopharmaceutical access and availability, 
TABLE 6

Commercial Radiopharmaceutical Kit Suppliers: Part 2

\begin{tabular}{|c|c|c|c|c|c|}
\hline Supplier & $\begin{array}{l}\text { Total no. of } \\
\text { countries }\end{array}$ & $\begin{array}{l}\text { United States } \\
\text { and Canada }\end{array}$ & Europe & Asia-Pacific & Africa \\
\hline Lantheus & 2 & 1 & & 1 & \\
\hline Pharmalucence & 2 & 1 & & 1 & \\
\hline Bracco & 1 & 1 & & & \\
\hline Ayto Pharma & 1 & 1 & & & \\
\hline Spectrum & 2 & 1 & 1 & & \\
\hline Radpharm & 1 & & & 1 & \\
\hline Ansto & 1 & & & 1 & \\
\hline Sirtex & 2 & & & 2 & \\
\hline Perkin Elmer & 1 & & & 1 & \\
\hline BAEC & 1 & & & 1 & \\
\hline Institute of Isotope Co. Ltd. & 1 & & & 1 & \\
\hline China Isotope Co. & 1 & & & 1 & \\
\hline Gipharma & 2 & & & 1 & 1 \\
\hline Sanofi & 1 & & & & 1 \\
\hline NTP & 1 & & & & 1 \\
\hline Ithema Labs & 1 & & & & 1 \\
\hline Shin Jin (Indonesia) & 1 & & & 1 & \\
\hline Kimia Farma (Indonesia) & 1 & & & 1 & \\
\hline Parsisotope (Iran) & 1 & & & 1 & \\
\hline IPEN & 1 & 1 & & & \\
\hline
\end{tabular}

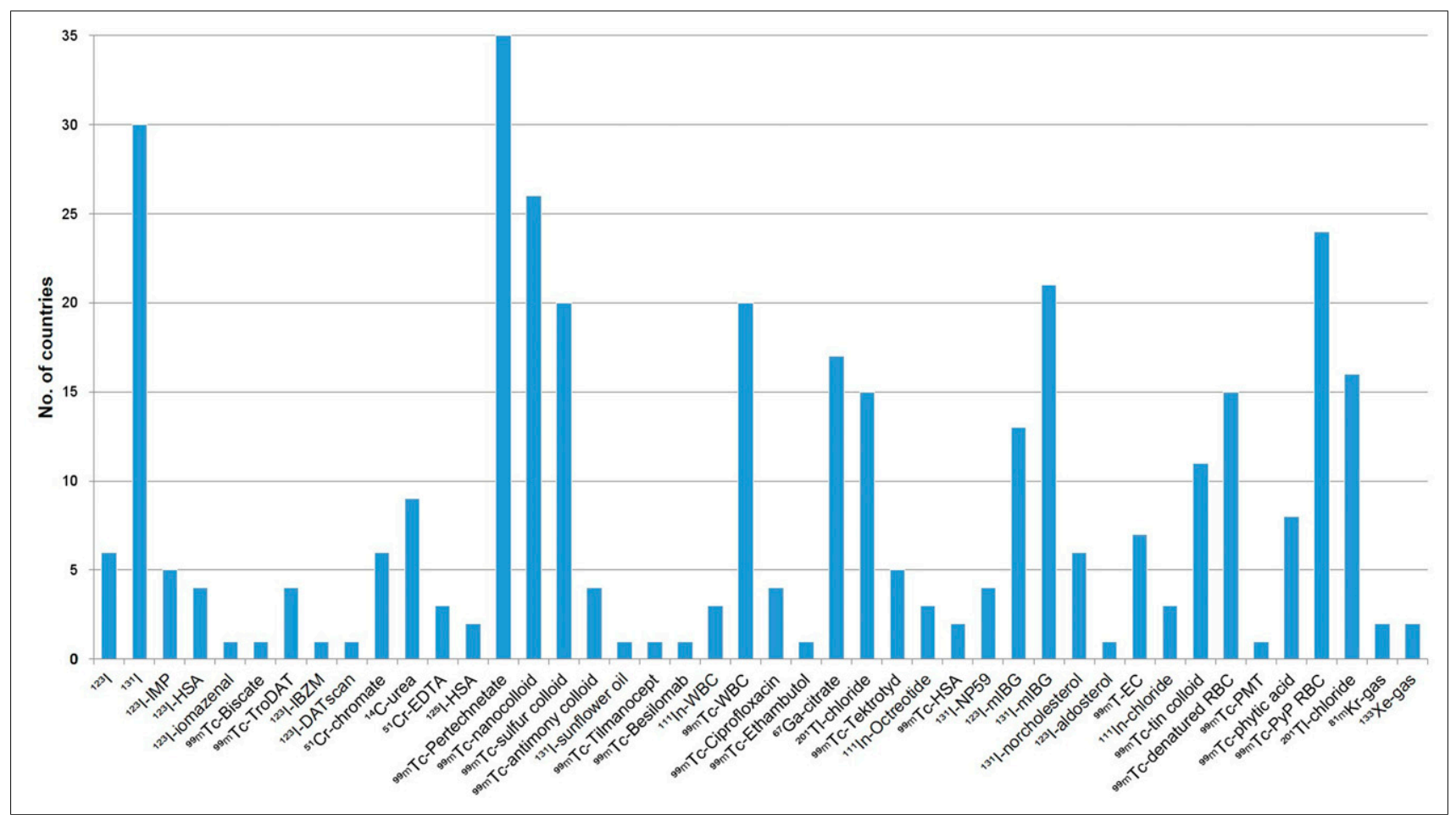

FIGURE 2. SPECT radionuclides and radiopharmaceuticals available in countries surveyed. 


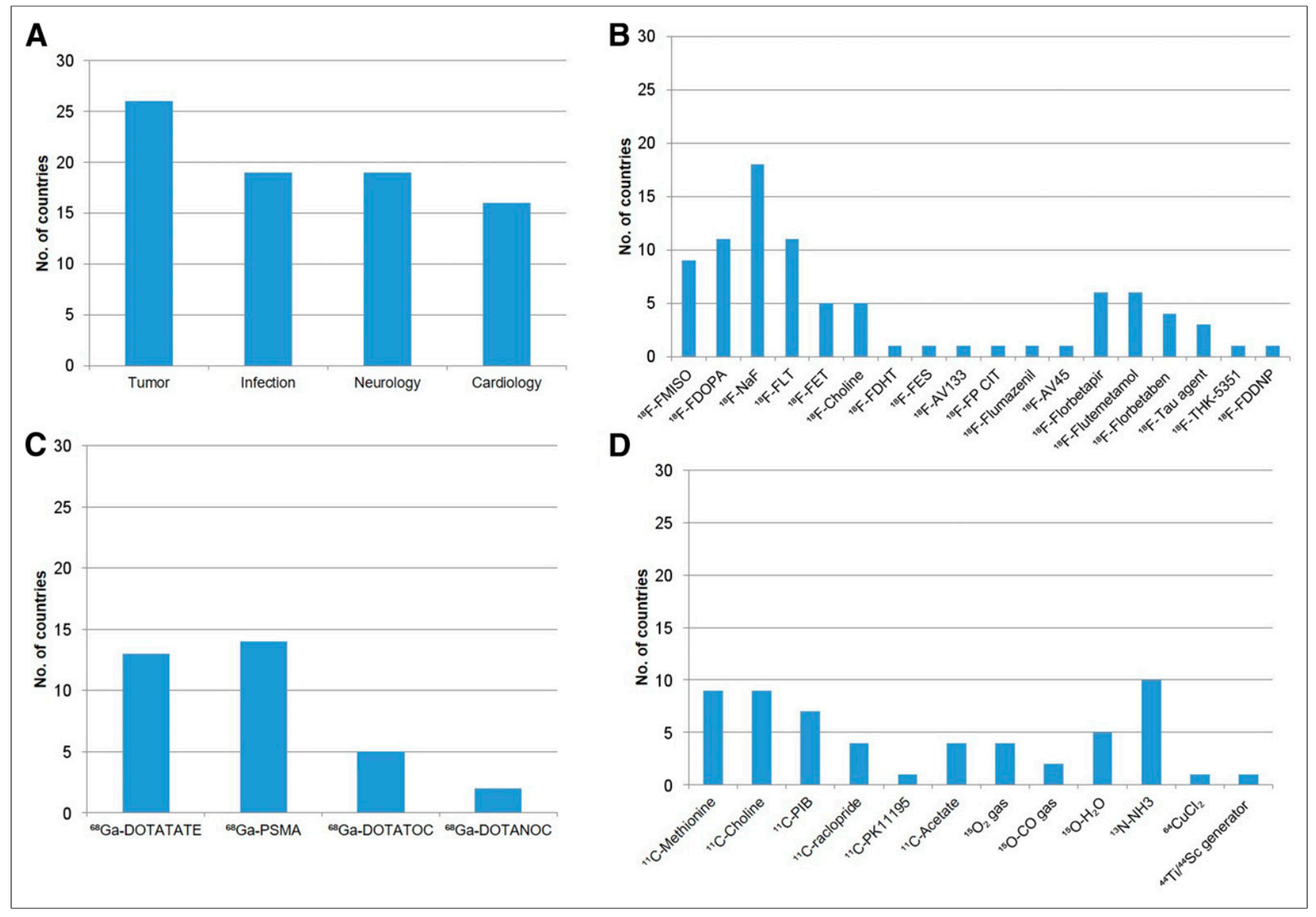

FIGURE 3. Number of countries with access to PET radiopharmaceuticals: ${ }^{18} \mathrm{~F}-\mathrm{FDG}$ clinical use (A), available ${ }^{18} \mathrm{~F}-\mathrm{labeled} \mathrm{PET}$ tracers (B), commonly used ${ }^{68}$ Ga-labeled tracers (C), and other PET tracers (D).

although the capability to address these issues varies according to the size of the country, funding, and nuclear medicine infrastructure (including workforce). Interestingly, the problems of limited suppliers of cold kits, and many diagnostic SPECT radiopharmaceuticals, were seen in low-, middle- and high-income countries globally, indicating the problem is not restricted just to countries with challenges in funding of nuclear medicine studies. Many of the workforce issues can be addressed in part by coordinated efforts to enhance training of physicians, technologists, and scientists in nuclear medicine; regional (e.g., SNMMI, European Association of Nuclear Medicine, and Asia

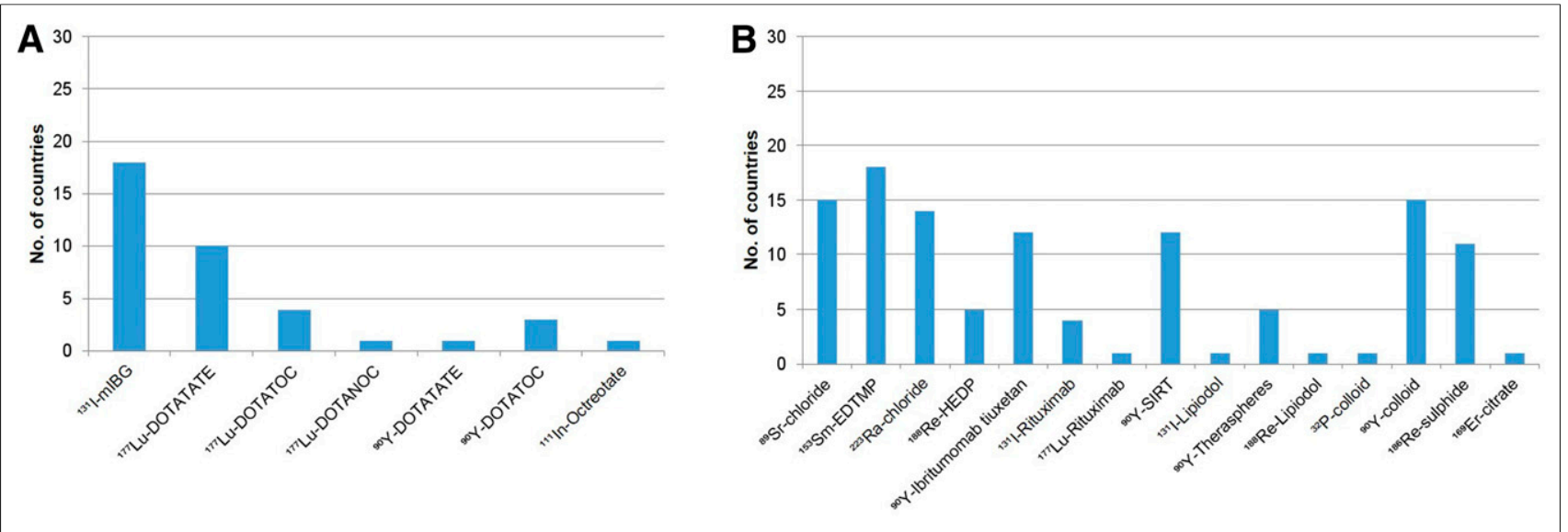

FIGURE 4. Number of countries with access to range of radionuclide therapies: targeted therapy (A) and radionuclide therapies currently used other than ${ }^{131} \mathrm{I}(\mathrm{B})$. 
Oceania Federation of Nuclear Medicine and Biology) as well as IAEA programs all play a part in supporting direct training, as well as documentation and position papers on protocols and infrastructure requirements. The ability of nuclear medicine societies to identify access issues and work with regional societies/associations to identify sources of radioisotopes and kits and facilitate local regulatory approvals may play a role. It is also important for companies and professional organizations (e.g., Nuclear Medicine Europe) to be involved in provision of supplies and stability of supply chains. Regional initiatives through IAEA and the World Health Organization may have a role in supporting access programs, particularly in low- and middle-income countries. In the context of personalized medicine and targeted therapies, and particularly in theranostics, strategic initiatives aimed at promoting the use and funding of SPECT and PET radiopharmaceuticals should align with drug development and approvals in countries. This would also benefit from cooperation and sharing of health technology assessments between countries, thus improving time to approvals and economic justification of new studies. Although global efforts to enhance access and availability of radiopharmaceuticals will also be subject to major industrywide events such as ${ }^{99} \mathrm{Mo}-{ }^{99 m} \mathrm{Tc}$ shortages, and more recently the COVID-19 pandemic which is impacting on global supply chains $(13-16,18)$, the importance of nuclear medicine in routine patient care should be a key driver of any approach.

\section{CONCLUSION}

This NMGI has revealed an interesting portrayal of the issues related to the supply, availability, cost, regulatory barriers, and other factors related to the use of radiopharmaceuticals internationally. Particularly surprising was the limited availability of standard diagnostic radiopharmaceuticals in many countries, particularly lowand middle-income countries. There are several strategic initiatives required to address the varied causes of reduced supply, ideally linking major industry and health organizations. Nuclear medicine is widely used and is expanding worldwide, and addressing the issues of access and availability of radiopharmaceuticals is a key strategy for ensuring patients can benefit from these vital imaging and therapeutic procedures.

\section{DISCLOSURE}

Support for this project was provided by the Society of Nuclear Medicine and Molecular Imaging (SNMMI). Andrew Scott is supported by NHMRC Senior Investigator Fellowship 1177837. No other potential conflict of interest relevant to this article was reported.

\section{ACKNOWLEDGMENTS}

We thank the leadership of the countries that contributed data for this project, as well as Virginia Pappas, Nikki Wenzel-Lamb, Bonnie Clarke, and Teresa Ellmer of the SNMMI for their support of this NMGI. We also acknowledge the input of Dr. Ravi Kashyap and Prof. Lin Li in the project.
KEY POINTS

QUESTION: What are the issues impacting access and availability of radiopharmaceuticals at a global level?

PERTINENT FINDINGS: Limited sources of radiopharmaceuticals and kits, supply chains, regulatory and reimbursement issues, and workforce are limitations to access.

IMPLICATIONS FOR PATIENT CARE: Strategic action to address these issues is required to ensure optimal availability of radiopharmaceuticals for patients in all countries.

\section{REFERENCES}

1. The supply of medical isotopes: an economic diagnosis and possible solutions. OECD iLibrary website. https://doi.org/10.1787/9b326195-en. Published November 18, 2019. Accessed October 28, 2020.

2. National Research Council and Institute of Medicine of the National Academies. Nuclear medicine imaging in diagnosis and treatment. In: Advancing Nuclear Medicine Through Innovation. National Academies Press; 2007:43-58.

3. Wu M, Shu J. Multimodal molecular imaging: current status and future directions. Contrast Media Mol Imaging. 2018;2018:1382183.

4. Cutler CS. Economics of new molecular targeted personalized radiopharmaceuticals. Semin Nucl Med. 2019;49:450-457.

5. IMAGINE: IAEA Medical imAGIng and Nuclear mEdicine global resources database. IAEA website. https://humanhealth.iaea.org/HHW/DBStatistics/IMAGINE. html. Accessed October 28, 2020.

6. Adedapo KS, Onimode YA, Ejeh JE, Adepoju AO. Avoidable challenges of a nuclear medicine facility in a developing nation. Indian J Nucl Med. 2013;28:195-199.

7. Dondi M, Kashyap R, Paez D, et al. Trends in nuclear medicine in developing countries. J Nucl Med. 2011;52(suppl 2):16S-23S.

8. Fahey FH, Bom HH, Chiti A, et al. Standardization of administered activities in pediatric nuclear medicine: a report of the first nuclear medicine global initiative project, part 1-statement of the issue and a review of available resources. $\mathrm{J} \mathrm{Nucl}$ Med. 2015;56:646-651.

9. Fahey FH, Bom HH, Chiti A, et al. Standardization of administered activities in pediatric nuclear medicine: a report of the first nuclear medicine global initiative project, part 2-current standards and the path toward global standardization. J Nucl Med. 2016;57:1148-1157.

10. World Bank country and lending groups. The World Bank website. https:// datahelpdesk.worldbank.org/knowledgebase/articles/906519-world-bank-countryand-lending-groups. Accessed October 28, 2020.

11. Eckelman W, Richards P, Hauser W, Atkins H. Technetium-labeled red blood cell. J Nucl Med. 1971;12:22-24.

12. Eckelman W. Instant 99mTc-DTPA. J Nucl Med. 1970;11:761.

13. Communication from the NMEu emergency response team (ERT) to the European observatory for the supply of radioisotopes for medical use: subject-possible impact of COVID-19 on global supply of Mo-99. Commercial Payments International website. https://cdn.ymaws.com/www.bnms.org.uk/resource/resmgr/radioisotope_supplies/aipes_or_oecd/ert_communication_9march_202.pdf. Published March 10, 2020. Accessed October 28, 2020.

14. IAEA webinar: coronavirus disease (COVID-19) pandemic - challenges for the nuclear medicine departments. IAEA website. https://humanhealth.iaea.org/HHW/ covid19/webinars.html. Published March 25, 2020. Accessed October 28, 2020.

15. Lam WW, Loke KS, Wong WY, et al. Facing a disruptive threat: how can a nuclear medicine service be prepared for the coronavirus outbreak 2020. Eur J Nucl Med Mol Imaging. 2020;47:1645-1648.

16. Czernin J, Fanti S, Meyer PT, et al. Nuclear medicine operations in the times of COVID-19: strategies, precautions, and experiences. J Nucl Med. 2020;61:626-629.

17. Decristoforo C, Lyashchenko SK. Recommendations for conducting clinical trials with radiopharmaceuticals. In: Volterrani D, Erba P, Carrió I, Strauss H, Mariani G, eds. Nuclear Medicine Textbook. Springer; 2019:1039-1050.

18. Paez D, Gnanasegaran G, Fanti S, et al. COVID-19 pandemic: guidance for nuclear medicine departments. Eur J Nucl Med Mol Imaging. 2020;47:1615-1619. 